\title{
Acil Operasyonlar ve Anestezi Dağılım Analizi: Retrospektif Çalışma
}

\section{Emergency Operations and Anesthesia Distribution Analysis: Retrospective Study}

Fatma Çelik ${ }^{1}$,

Recai Dağlı ${ }^{1}$,

Mehmet Cantürk ${ }^{2}$

${ }^{1}$ Kırşehir Ahi Evran Üniversitesi Tıp Fakültesi Anesteziyoloji ve Reanimasyon Anabilim Dalı, Kırşehir, Türkiye

${ }^{2}$ Kırşehir Ahi Evran Üniversitesi Eğitim ve Araştırma Hastanesi Anesteziyoloji ve Reanimasyon Kliniği, Kırşehir, Türkiye

Geliş Tarihi/Received: 11 Ekim 2018 Kabul Tarihi/Accepted: 1 Ocak 2019

Yazışma Adresi: Fatma Çelik, Kırşehir Ahi Evran Üniversitesi Tıp Fakültesi Anesteziyoloji Reanimasyon Anabilim Dalı, Kırşehir, Türkiye e-posta: fatma.celik@ahievran.edu.tr

\section{ORCID}

Fatma Çelik

https://orcid.org/0000-0003-0192-0151

\begin{abstract}
Öz
Amaç: Çalışmanın amacı acil operasyona alınan hastaların, anestezi uygulamalarını epidemiyolojik açıdan değerlendirmektir.

Hastalar ve Yöntem: Bu retrospektif çalışmada, Ocak 2016 - Aralık 2017 tarihleri arasında acil anestezi uygulanan 1523 hastanın verileri gözden geçirildi. Anestezi izlem kayıtları; demografik özellikler, cerrahi branşlar, operasyon tipleri, anestezi yöntemleri, Amerikan Anestezistler Derneği ASA fiziksel durum sınıflandırması, operasyon süresi, kullanılan kan ve kan ürünleri, postoperatif yoğun bakım ihtiyaçları, nöromüsküler blok antagonizma yöntemi ve mortalite oranları açısından incelendi.

Bulgular: Hastaların yaş ortalaması $30.96 \pm 15.44$ (2-92) yıl olarak tespit edildi. Hastaların 1032's (\%67.8) kadın, 491'i (\%32.2) erkekti. En sık yapılan operasyonlar; $722(\% 47.4)$ sezaryen ve $301(\% 19.8)$ apendektomi olduğu tespit edildi. Anestezi yöntem sıklığı sırasıyla $936(\% 61,6)$ genel anestezi, $403(\% 26,4)$ rejyonel anestezi ile birlikte sedoanaljezi, 177 (\%11.6) rejyonel anestezi, $4(\% 0.2)$ sedoanaljezi olarak belirlendi. Ortalama operasyon süresi $54.38 \pm 41.90 \mathrm{dk}$. (5-390) idi. Hastaların 347 'sinde traneksamik asit, 48'inde eritrosit süspansiyonu, 1 'inde trombosit süspansiyonu, 31'inde taze donmus plazma kullanıldığ belirlendi. Postoperatif yoğun bakım intiyacı 64 (\%4.2) hastada görüldü. Hastaların 29'u (\%1.9) entübe olarak yoğun bakım ünitesine transfer edildi. Mortalite oranı $3(\% 0.19)$ olarak saptandı.

Sonuç: Acil cerrahi operasyon olarak en fazla sezaryen ve akut apendektomi yapılmıștır. Acil cerrahi operasyonlarda, genel anestezi rejyonel anesteziden daha fazla tercih edilmiştir. Postoperatif yoğun bakım ünitesine transfer, ileri yaş ve yüksek ASA skoruna sahip hastalarda uygulanmıştır.
\end{abstract}

Anahtar Kelimeler: Anestezi, genel anestezi, mortalite, acil operasyon, epidemiyoloji

\section{Abstract}

Aim: The aim of this study is to evaluate the epidemiological aspects of anesthesia practices in patients undergoing emergency operation.

Patients and Methods: In this retrospective study, data of 1523 patients who underwent emergency anesthesia between January 2016 - December 2017 were reviewed. Anesthesia monitoring records were examined in terms of demographic features, surgical branches, operation types, anesthesia methods American Society of Anesthesiologists (ASA) physical status classification, operation time, blood and blood products used, postoperative intensive care needs, neuromuscular block antagonism method and mortality rates.

Results: The mean age of the patients was $30.96 \pm 15.44(2-92)$ years. $1032(67.8 \%)$ of the patients were female and $491(32.2 \%)$ were male. The most common operations; $722(47.4 \%)$ had caesarean section and 301 (19.8\%) appendectomy. The frequency of anesthesia was determined as $936(61.6 \%)$ general anesthesia, $403(26.4 \%)$ regional anesthesia together with sedoanalgesia, 177 (11.6\%) regional anesthesia and $4(0.2 \%)$ sedoanalgesia. The mean operation time was $54.38 \pm 41.90 \mathrm{~min}$. (5-390) Tranexamic acid was used in 347 patients, erythrocyte suspension in 48 patients, thrombocyte suspension in 1 , fresh frozen plasma in 31 patients. The need for postoperative intensive care was seen in 64 (4.2\%) patients. $29(1.9 \%)$ of the patients were transferred to the intensive care unit with intubated. The mortality rate was $3(0.19 \%)$

Conclusion: The most frequent cesarean section and acute appendectomy were performed as emergency surgery. In emergency surgery, general anesthesia was preferred more than regional anesthesia. Transfer to the postoperative intensive care unit was performed in patients with advanced age and high ASA score.

Keywords: Anesthesia, general anesthesia, mortality, emergency operation, epidemiology

\section{GíRiş}

Acil cerrahi operasyon geçiren hastalar, sınırlı preoperatif anestezi hazırlık süresi nedeniyle, yüksek mortalite ve morbiditeye neden olabilecek risklere sahiptir $(1,2)$. Bu risk faktörleri arasında; özellikle yenidoğan ve geriartik hasta grubu olmak üzere hastanın yaşı (3-5), Amerikan Anestezistler Derneği (ASA) fiziksel durum sınıfı $(4,5)$, sıvı elektrolit imbalansı (6), hemodinamik instabilite, hava yolu güvenliğini sağlayabilmek için gerekli ön hazırlığın yapılamaması (7-10), dolu mide ve aspirasyon riski (2, 11), mevcut eşlik eden hastalıkları (5), kan kaybı (12, 13), cerrahi bölgenin özellikleri (14), travmanın çeşidi ve şiddeti sayılabilir $(1,3,6)$. Elektif operasyonlar ile karşılaştırıldığında, acil cerrahi uygulanacak hastalarda morbidite ve mortalite daha yüksektir $(5$,

Atıf yapmak için: Çelik F, Dağlı R, Cantürk M. Acil Operasyonlar ve Anestezi Dağılım Analizi: Retrospektif Çalışma. Selcuk Med J 2019;35(4): 235-241 
15). Bu sebeple acil operasyonlar için mevcut durum olabildiğince hızlı değerlendirilip gerekli önlemler alınmalıdır.

Amacımız; hastanemizde iki yıl süresince acil anestezi uygulanan hastaların demografik özellikleri, operasyon tipleri, uygulanan anestezi yöntemleri, ASA sınıflandırması, operasyon süresi, kullanılan kan ve kan ürünleri, postoperatif yoğun bakım intiyaçları, uygulanan nöromüsküler blok (NMB) antagonizması ve mortaliteleri ile ilgili dağılım analizini epidemiyolojik çalışmalar için ortaya koymaktır.

\section{HASTALAR VE YÖNTEM}

Kırşehir Ahi Evran Üniversitesi Tıp Fakültesi Klinik Araştırmalar Etik Kurul (Karar No:2018-01/13 Tarih: 09/01/2018) kararı sonrası 1523 hasta verisi; preoperatif değerlendirme formları, anestezi izlem kayıtları ile bilgisayar kayıtları üzerinden retrospektif olarak incelendi.

Ocak 2016 - Aralık 2017 tarihleri arasında acil anestezi uygulanan hastaların verileri incelendi. Yaş dağılımı dekatlar halinde on gruba ayrıldı. Cerrahi branşlar; Genel Cerrahi, Kadın Hastalıkları ve Doğum (KHD), Nöroşirurji, Plastik ve Rekonstrüktif Cerrahi, Ortopedi, Kardiyovasküler Cerrahi (KVC), Üroloji, Kulak Burun Boğaz (KBB), Göğüs Cerrahi, Diş Hekimliği ve Göz klinikleri olarak kaydedildi. Operasyon tipi; Akut batın, sezaryen, apendektomi, KHD diğer aciller, kolesistektomi, genel cerrahi diğer aciller, kırıklar, üroloji acilleri, plastik ve rekonstrüktif cerrahi acilleri, nöroşirurji acilleri, KVC acilleri, ortopedi diğer acilleri, KBB acilleri, göğüs cerrahi acilleri ve diş acil operasyonları şeklinde gruplandırıldı.

ASA fiziksel durum sınıflandırması I-VI arasında sınıflandırılmaktadır ve acil cerrahi operasyonlarda hastanın sınıflama numarasından sonra $E$ (Emergency) harfi eklenmektedir. Hastalar ASA I-E, ASA II-E, ASA III-E, ASA IV-E, ASA V-E ve ASA VI-E olarak tanımlanıp incelendi (16). Anestezi yöntemi; Genel anestezi, rejyonel anestezi, rejyonel anestezi ile birlikte sedoanaljezi ve sedoanaljezi olmak üzere 4 grupta incelendi. Operasyon süresi; 60 dk'dan az, 60-119 dk, 120-179 dk ve 179 dk'da uzun süren operasyonlar şeklinde gruplandırıldı. Kullanılan kan ve kan ürünleri; Traneksamik asit (amp), fibrinojen (flk), eritrosit süspansiyonu (ünite), trombosit süspansiyonu (ünite), taze donmuş plazma (TDP) (ünite) şeklinde değerlendirildi. Nöromüsküler blok antagonizması; Neostigmine ve atropine, sugammadeks ve nöromüsküler blok antagonizması yok şeklinde 3 grupta incelendi. Hastaların postoperatif yoğun bakım ihtiyacı ve perioperatif mortalite oranları incelendi. Operasyon odası ve postoperatif derlenme ünitesinde ortaya çıkan ölümler perioperatif mortalite olarak tanımlandı.

\section{İstatistik:}

Verilerin analizinde IBM SPSS Ver 19.0 (SPSS, Inc., Chicago, IL, USA) paket programı kullanıldı. Çalışma verileri değerlendirilirken tanımlayıcı istatistiksel metotlar yüzde, ortalama, standard deviasyon, ortanca (minimum-maksimum) ve sayı (n) olarak verildi.

\section{BULGULAR}

Kırşehir Ahi Evran Üniversitesi Eğitim ve Araştırma Hastanesi'nde operasyona alınan 17323 vakanın 1523'üne acil anestezi uygulanmıştır. Hastaların yaş ortalaması $30.96 \pm 15.44$ (2-92) yıl olarak saptandı. Hastaların yaş, cinsiyet ve ASA fiziksel durum dağılımı Tablo 1'de verilmiştir. Acil operasyon gerçekleştiren cerrahi branşlar sıklıkla Kadın Hastalıkları ve Doğum $(n=753, \% 49.4)$, Genel Cerrahi $(n=591, \% 38.9)$, Üroloji ( $n=63, \% 4.1)$ olarak saptandı (Tablo 2). En sık alınan acil operasyon tipi sırasıyla sezaryen $(n=722, \% 47.4)$, apendektomi $(n=301, \% 19.8)$ ve akut batın ( $n=229, \% 15)$ operasyonları olduğu tespit edildi (Tablo 3).

Anestezi yöntemi değerlendirildiğinde; hastaların, 939'una (\%61.6) genel anestezi, 177'sine (\%11.6) tercih edildiği görüldü. Operasyon tipine göre uygulanan anestezi yöntemleri Tablo 4'de verilmiştir.

Tablo 1. Hastaların demografik özellikleri ve ASA skor dağılımı

\begin{tabular}{llll}
\hline & & $\mathbf{n}$ & $\%$ \\
\hline Yaş & $0-9$ & 40 & 2.6 \\
& $10-17$ & 134 & 8.8 \\
& $18-29$ & 692 & 45.4 \\
& $30-39$ & 348 & 22.8 \\
& $40-49$ & 120 & 7.9 \\
& $50-59$ & 84 & 5.5 \\
& $60-69$ & 47 & 3.1 \\
& $70-79$ & 37 & 2.4 \\
Cinsiyet & $80-89$ & 17 & 1.1 \\
& $90-100$ & 4 & 0.3 \\
& Kadın & 1032 & 67.8 \\
& Erkek & 491 & 32.2 \\
& I-E & 1088 & 71.4 \\
& II-E & 302 & 20.0 \\
& III-E & 80 & 5.3 \\
& IV-E & 46 & 3.0 \\
& V-E & 7 & 0.3 \\
\hline
\end{tabular}

ASA: Amerikan Anestezistler Derneği 
Tablo 2. Hastaların cerrahi branşlara göre dağılımı

\begin{tabular}{lll}
\hline Cerrahi Branş & $\mathbf{n}$ & $\%$ \\
\hline Genel Cerrahi & 591 & 38.9 \\
Kadın Hastalıkları ve Doğum & 753 & 49.4 \\
Nöroşirurji & 27 & 1.8 \\
Plastik ve Rekonstrüktif Cerrahi & 10 & 0.7 \\
Ortopedi & 49 & 3.2 \\
Kardiyovasküler Cerrahi & 15 & 1.0 \\
Üroloji & 63 & 4.1 \\
Kulak Burun Boğaz & 10 & 0.7 \\
Göğüs Cerrahi & 3 & 0.2 \\
Diş Hekimliği & 1 & 0.1 \\
Göz & 1 & 0.1
\end{tabular}

Acil kolesistektomi ve acil apendektomi operasyonları hariç tutulup intraabdominal cerrahi operasyonlar akut batın adı altında sınıflandırılmıştır. Akut batın operasyonu geçiren 229 hastanın 155'ine (\%67.7) genel anestezi, 17'sine (\%7.4) rejyonel anestezi, 57'sine (\%24.9) rejyonel anestezi ile birlikte sedoanaljezi uygulanmıştır. Acil kolesistektomi operasyonu geçiren 17 hastanın 9'una (\%52.9) genel anestezi, 2'sine (\%11.8) rejyonel anestezi, 6'sına (\%35.3) rejyonel anestezi ile birlikte sedoanaljezi uygulanması dikkat çekici idi. Rejyonel anestezi uygulanan 8 hastada, bu anestezi yönteminin tercih edilme sebebi yüksek ASA skoruna bağlandı (Tablo 4). Rejyonel anestezi uygulanan hastalara yüksek seviyede (T4 dermatomunu içine alacak şekilde) blok uygulandı ve hastanın toleransına göre sedoanaljezi eklendi. Vakaların ortalama operasyon süresi 54.38 $\pm 41.90 \mathrm{dk}$ (5-390) idi. Operasyon tipine göre
Tablo 3. Hastaların operasyon tipine göre dağılımı

\begin{tabular}{lll}
\hline Operasyon Tipi & $\mathbf{n}$ & \% \\
\hline Akut Batın & 229 & 15,0 \\
Sezaryen & 722 & 47,4 \\
Apendektomi & 301 & 19,8 \\
Diğer Kadın Hastalıkları & 16 & 1,1 \\
ve Doğum Aciller & & \\
Diğer Genel Cerrahi Aciller & 59 & 3,9 \\
Kırıklar & 27 & 1,8 \\
Ürolojik Aciller & 62 & 4,1 \\
Plastik ve Rekonstrüktif Cerrahi & 9 & 0,6 \\
Aciller & & \\
Nöroşirurji Aciller & 26 & 1,7 \\
Kardiyovasküler Cerrahi Aciller & 15 & 1,0 \\
Diğer Ortopedi Aciller & 27 & 1,8 \\
Kolesistektomi & 17 & 1,1 \\
Kulak Burun Boğaz Aciller & 10 & 0,7 \\
Göğüs Cerrahi Aciller & 2 & 0,1 \\
Diş Aciller & 1 & 0,1 \\
\hline
\end{tabular}

operasyon süresi 60 dakikadan az süren operasyonlar, 60-119 dk. arası süren operasyonlar, 120-179 dk. arası süren operasyonlar, 179 dk.'dan uzun süren operasyonlar şeklinde sınıflandırıldı (Tablo 5).

Kullanılan kan ve kan ürünleri incelenmesinde, en fazla sezaryen operasyonlarında olmak üzere 347 hastada traneksamik asit kullanıldı. 48 hastada eritrosit süspansiyonu, 1 hastada trombosit süspansiyonu ve 31 hastada TDP kullanıldı. Genel anestezi uygulanan 939 (\%61.6) hastanın nöromüsküler blok antagonizması incelendiğinde, 233 (\%24.8) hastada neostigmin ve atropin, 650 (\%69.2) hastada sugammadeks kullanıldığı görüldü.

Tablo 4. Hastaların operasyon tipine göre uygulanan anestezi yöntemi dağılımı

\begin{tabular}{|c|c|c|c|c|c|}
\hline Operasyon Tipi & $\begin{array}{l}\text { Genel } \\
n(\%)\end{array}$ & $\begin{array}{l}\text { Rejyonel } \\
n(\%)\end{array}$ & $\begin{array}{l}\text { Anestezi Yöntemi } \\
\text { Rejyonel+Sedasyon } \\
n(\%)\end{array}$ & $\begin{array}{l}\text { Sedoanaljezi } \\
n(\%)\end{array}$ & $\begin{array}{l}\text { Total } \\
\text { n(\%) }\end{array}$ \\
\hline Akut Batın & $155(67.7)$ & $17(7.4)$ & $57(24.9)$ & $0(0.0)$ & $229(100)$ \\
\hline Sezaryen & $430(59.6)$ & $93(12.9)$ & $199(27.5)$ & $0(0.0)$ & $722(100)$ \\
\hline Apendektomi & $177(58.8)$ & $39(13)$ & $85(28.2)$ & $0(0.0)$ & $301(100)$ \\
\hline $\begin{array}{l}\text { Diğer Kadın Hastalıkları ve } \\
\text { Doğum Aciller }\end{array}$ & $11(68.8)$ & $2(12.5)$ & $3(18.7)$ & $0(0.0)$ & $16(100)$ \\
\hline Diğer Genel Cerrahi Aciller & $36(61)$ & $10(16.9)$ & $11(18.7)$ & $2(3.4)$ & $59(100)$ \\
\hline Kırıklar & $20(74.1)$ & $2(7.4)$ & $4(14.8)$ & $1(3.7)$ & $27(100)$ \\
\hline Üroloji & $42(67.7)$ & $7(11.3)$ & $13(21.0)$ & $0(0.0)$ & $62(100)$ \\
\hline Plastik ve Rekontrüktif Cerrahi & $7(77.8)$ & $0(0.0)$ & $2(22.2)$ & $0(0.0)$ & $9(100)$ \\
\hline Nöroşirurji & $14(53.8)$ & $1(3.8)$ & $11(42.4)$ & $0(0.0)$ & $26(100)$ \\
\hline Kardiyovasküler Cerrahi & $11(73.3)$ & $1(6.7)$ & $3(20.0)$ & $0(0.0)$ & $15(100)$ \\
\hline Diğer Ortopedi Aciller & $16(59.3)$ & $3(11.1)$ & $8(29.6)$ & $0(0.0)$ & $27(100)$ \\
\hline Kolesistektomi & $9(52.9)$ & $2(11.8)$ & $6(35.3)$ & $0(0.0)$ & $17(100)$ \\
\hline Kulak Burun Boğaz & $9(90.0)$ & $0(0.0)$ & $0(0.0)$ & $1(10.0)$ & $10(100)$ \\
\hline Göğüs Cerrahi & $1(50.0)$ & $0(0.0)$ & $1(50.0)$ & $0(0.0)$ & $2(100)$ \\
\hline Diş & $1(100.0)$ & $0(0.0)$ & $0(0.0)$ & $0(0.0)$ & $1(100)$ \\
\hline
\end{tabular}


Tablo 5. Hastaların operasyon tipine göre operasyon süresi dağılımı

\begin{tabular}{lllll}
\hline & & \multicolumn{2}{c}{ Operasyon Süresi (dakika) } \\
Operasyon Tipi & $\mathbf{6 0}$ & $\mathbf{6 0 - 1 1 9}$ & $\mathbf{1 2 0 - 1 7 9}$ & $\mathbf{1 7 9}$ \\
$\mathbf{n}(\mathbf{n}(\mathbf{1 7 9})$ & $\mathbf{n}(\%)$ \\
\hline Akut Batın & $\mathbf{n}(\%)$ & $71(31)$ & $29(12.6)$ & $15(6.6)$ \\
Sezaryen & $114(49.8)$ & $76(10.5)$ & $6(0.9)$ & $0(0.0)$ \\
Apendektomi & $640(88.6)$ & $70(23.3)$ & $14(4.6)$ & $1(0.3)$ \\
Diğer Kadın Hastalıkları ve Doğum Aciller & $216(71.8)$ & $7(43.8)$ & $2(12.4)$ & $0(0.0)$ \\
Diğer Genel Cerrahi Aciller & $7(43.8)$ & $12(20.3)$ & $11(18.7)$ & $3(5.1)$ \\
Kırıklar & $33(55.9)$ & $12(44.4)$ & $11(40.8)$ & $3(7.4)$ \\
Üroloji & $2(7.4)$ & $16(25.8)$ & $4(6.5)$ & $2(3.2)$ \\
Plastik ve Rekontrüktif Cerrahi & $40(64.5)$ & $2(22.2)$ & $1(11.1)$ & $0(0.0)$ \\
Nöroşirurji & $6(66.7)$ & $7(26.9)$ & $8(30.8)$ & $9(34.6)$ \\
Kardiyovasküler Cerrahi & $2(7.7 \%)$ & $8(53.3)$ & $1(6.7)$ & $2(13.3)$ \\
Diğer Ortopedi Aciller & $4(26.7)$ & $9(33.3)$ & $2(7.4)$ & $1(3.7)$ \\
Kolesistektomi & $15(55.6)$ & $8(47.1)$ & $3(17.6)$ & $3(17.6)$ \\
Kulak Burun Boğaz & $3(17.6)$ & $2(20.0)$ & $0(0.0)$ & $0(0.0)$ \\
Göğüs Cerrahi & $8(80.0)$ & $1(50)$ & $0(0.0)$ & $0(0.0)$ \\
Diş & $1(50)$ & $0(0.0)$ & $0(0.0)$ & $0(0.0)$ \\
\hline
\end{tabular}

Postoperatif yoğun bakım intiyacı 64 (\%4.2) hastada görüldü. Bu hastaların 29'u (\%1.9) entübe olarak yoğun bakım ünitesine transfer edildi. Mortalite ve ASA ilişkisi incelendiğinde, ASA V-E grubundaki 7 vakadan 3'ünün intraoperatif mortalite ile sonlandığı tespit edildi (Tablo 6).

\section{TARTIŞMA}

Anestezi yaygın olarak yüksek riskli bir aktivite olarak kabul edilir $(17,18)$. Çünkü anestezi uygulaması morbidite ve mortaliteye yol açabilecek fizyolojik değişiklikleri indükleme potansiyeline sahiptir (18). Güvenli, etkili cerrahi girişim ve anestezi uygulaması optimize edilmiş hasta gerektirir. Epidemiyolojik çalışmaların birçoğu, hastaların preoperatif hazırlıklarının yetersiz olmasının, perioperatif mortalitenin primer nedenleri için önemli bir faktör olabileceğini göstermiştir. Bununla birlikte acil cerrahi operasyonlar; yeterli preoperatif değerlendirmeye fırsat vermediğinden, elektif cerrahilerden daha yüksek riskesahiptir(19). Örneğin perioperatifkardiyak arrest insidansı açısından değerlendirildiğinde; acil cerrahi operasyon için anestezi alan hastalarda kardiyak arrest, elektif cerrahi vakaların iki katından daha fazla ve aynı zamanda mortalite oranı anlamlı derecede yüksek oranda bulunmuştur (1). Yine yapılan iki çalışma, cerrahi hastalardaki tüm kardiyak arrest olaylarının \%50-60'ının acil cerrahi operasyon geçiren hastalarda meydana geldiğini bildirmiştir (1). Gelişmekte olan ülkelerde, tüm perioperatif kardiyak arrest insidansı 10000 'de 2.99-40.4 arasında değişirken acil cerrahi operasyonlarda insidans 10000 'de 6.48-62.1 arasında değişen artışa neden olmuştur (1). Yaşlanma ile birlikte fizyolojik rezervde azalma, anatomik ve farmakolojik değişikliklerin yanı sıra eşlik eden hastalıkların geriatrik hasta grubunda, acil operasyon mortalite riskini artırdığı bilinmektedir (3). Dahası, yenidoğanlarda ve bir yaşın altındaki çocuklarda ve yaşılırda mortalite oranları genç erişkinlerden daha yüksektir (4). Çalışmamızda 21(\%1.4) hastanın 80 yaş üstü olduğu görüldü. Genç ve kadın hasta sayısının fazla olması, operasyon tipi olarak en sık sezaryen operasyonlarının alınması ile ilişkilendirildi.

Acil operasyonların anestezi tekniği seçiminde, cerrahi teknik ve anestezistin tercihi rehberlik eder. Acil operasyonlar için genel anestezi kadar rejyonel anestezi de kullanılabilir. Ancak, aciliyet nedeniyle,

Tablo 6. Mortalite ile ASA dağılımı

\begin{tabular}{lcccccc}
\hline & & & \multicolumn{2}{c}{ Total } & & \\
ASA & & ASA I-E & ASA II-E & ASA III-E & ASA IV-E & ASA V-E \\
\hline Mortalite & Yok & 1088 & 302 & 80 & 46 & 4 \\
& Var & 0 & 0 & 0 & 0 & 3 \\
Total & & 1088 & 302 & 80 & 46 & 7 \\
\hline
\end{tabular}


genel anestezi rejyonel anesteziye göre daha sık kullanılmaktadır. Çünkü genel anestezi indüksiyonu için gereken süre belirgin olarak daha azdır (6). Özmen et al. 2006-2015 yılları arasında on yıllık acil operasyonlarının değerlendirilmesinde, acil sezaryen hastalarının 3958'ine (\%16) genel anestezi, 20455 'ine (\%84) rejyonel anestezi uygulamışlardır. Yılların dağılımı incelendiğinde, günümüze doğru gelindikçe rejyonel anestezi uygulama oranı artış göstermektedir (20). Hindistan'da 2010-2017 yılları arasında acil sezaryen operasyonuna alınan 19508 hastanın 1389'una (\%7.12) genel anestezi, 18119'una (\%92.87) rejyonel anestezi uygulanmıştır (21). Günümüzde, rejyonel anestezi uygulamasına yönelim artarken bizim çalışmamızda, genel anestezinin daha çok tercih edildiği görüldü. En sık operasyon tipi olarak tespit edilen sezaryen hastalarının da 430'unda (\%59.6) genel anestezi uygulanmıştır. Hastanemizde anestezist ve cerrah tarafından, bilinen bir kontrendikasyon yoksa, anestezi yöntemi hakkında hasta bilgilendirilmesine fırsat verilecek yeterli süre mevcut ise, hasta isteği göz önünde bulundurulmaktadır. Genel anestezi uygulama oranının yüksekliğinde, hasta bilgilendirilmesinin yeterli düzeyde yapılamaması primer etken olarak düşünüldü. Bununla birlikte genel anestezi tercihinin; cerrah ve anestezistin tercihi ile mi yoksa acil operasyon tanısı ve tekniğinden mi kaynaklandığını saptamak amacıyla farklı araştırmalar planlandı.

ASA fiziksel durum skoru, hastaya uygulanacak anestezik yaklaşımın ve özellikle monitorizasyon yöntemlerinin belirlenmesi, perioperatif mortalite ve morbiditelerini öngörebilmek amacıyla, preoperatif olarak hastanın sınıflandırıldığı bir değerlendirme sistemidir $(22,23)$. Acil cerrahiler ile birlikte yüksek ASA skoruna sahip hastalar perioperatif mortalitede risk faktörü olarak rapor edilmiştir (4). Brezilya merkezli bir çalışmada; 1996-2005 yılları arasında elektif ve acil olarak operasyona alınan 53718 hastanın operasyon odası ve postoperatif derlenme ünitesindeki perioperatif mortalite oranı $\% 0.22$ bildirilmiştir (5). Gabriel et al. Amerika Birleşik Devletleri'nde, 2010-2015 yılları arasında yapılan çok merkezli çalışmada; operasyon odası ve postoperatif derlenme ünitesindeki perioperatif mortalite oranı \%0.28 bildirilmiştir. Acil cerrahi operasyon geçiren ve genel anestezi uygulanan 49196 yetişkin hasta analiz edilmiştir. Kardiyak ve obstetrik acil cerrahiler çalışma dışı bırakılmıştır (24). Aksine, çalışmamız özellikli bir yaş aralığı, herhangi bir anestezi yöntemi veya cerrahi branş ile sınırlandırılmamıştır. Acil olarak operasyona alınan tüm hastalar kabul edilirken, elektif operasyonlar çalışma dışı bırakılmıştır. ASA V-E olarak operasyona alınan 7 hastanın 3'ü intraoperatif exitus ile sonuçlandığı saptanmıştır. ASA V-E skoruna sahip hastaların trafik kazalarına bağlı multitravmalı, şok tablosu halinde oparasyona alındıkları tespit edilmiştir. Perioperatif mortalite oranı \%0,19 olarak tespit edilmiştir. Mortalite oranımız literatürlerde bildirilenlere benzer şekilde saptanmıştır. Hastanemizin şehirlerarası yol üzerinde olmasının mortalite oranını olumsuz yönde etkilediği kanaatindeyiz.

Nöromüsküler blok (NMB), cerrahi işlemlerde trakeal entübasyonu kolaylaştırmak ve hasta hareketini en aza indirmek için yaygın olarak kullanılır. Cerrahi sonrası, nöromüsküler blokajın hızlı bir şekilde antagonize edilmesi ile hasta morbiditesini artırabilecek hipoksi, solunum zayıflığı ve yetmezliği gibi postoperatif komplikasyonları önlemek, hasta konforu ve güvenliğini iyileştirmek arzulanır (25). Rokuronyum veya vekuronyumun neden olduğu nöromüsküler bloğun antagonize edilmesi için sugammadeks doz uygulamasında üç yönetim programı önerilmiştir: Eğer orta NMB tespit edilmişse (train of four (TOF) en az 2 kasılma veriyorsa) $2 \mathrm{mg} /$ $\mathrm{kg}$; derin NMB tespit edilmişse (posttetanik sayım (PTC) 1-2 ise) $4 \mathrm{mg} / \mathrm{kg}$; veya çok derin NMB varsa (1.2 $\mathrm{mg} / \mathrm{kg}$ rokuronyum uyguladıktan $3 \mathrm{dk}$ sonra) $16 \mathrm{mg} /$ kg dozda kullanılması önerilmektedir. Rokuronyum ve vekuronyumun neden olduğu orta NMB'ta; 2 mg/ kg sugammadeks uygulaması ile hastaların sırasıyla $\% 96$ ve \%86'sında, 5 dakika içinde TOF oranı 0.9'a geri dönmüştür. Benzer şekilde, derin NMB'ta; sugammadeks $4 \mathrm{mg} / \mathrm{kg}$ verilen hastaların sırasıyla \% 95 ve \% 77'si 5 dakika içinde geri dönmüştür. Buna karşılık, neostigmin ile orta veya derin nöromüsküler blokta tedavi edilen çok az hasta, 5 dakika içinde geri döndürülmüştür (26).

Yapılan bir başka çalışmada; $2 \mathrm{mg} / \mathrm{kg}$ sugammadeks, rokuronyumun neden olduğu orta derecede nöromüsküler bloğun hızlı ve tam tersine dönmesini sağlamıştır. TOF oranının 0.9'a ulaşma süresi, sugammadeks ile neostigmin oranından ( 8.1 kat) daha hızlı olmuştur $(P<0.0001)$ (25). Sugammadeks klinik olarak anlamlı derecede daha hızlı bir şekilde orta ve derin blokajı tersine çevirerek spontan iyileşmeye ve neostigmine karşı orta derecede blokajın daha hızlı bir şekilde tersine çevrilmesini sağlamıştır (26). Sugammadeks ile nöromüsküler bloğun antagonize edilmesini takiben rezidü NMB insidansının ve rekürarizasyonun daha düşük olduğu 
gösterilmiştir $(25,26)$. Bizim araştırmamızda da; bu çalışmaların sonuçlarına bağlı olarak, daha hızlı bir antagonizma sağlaması, rezidü NMB insidansının daha az olması nedeniyle antagonizma için sıklıkla sugammadeks kullanıldığı tespit edildi.

İleri yaşlı, yüksek ASA fiziksel durum skoruna sahip veya multitravmalı $64(\% 4.2)$ hasta postoperatif yoğun bakım intiyacı gösterdi. Postoperatif entübe olarak 29 (\%1.9) hasta yoğun bakım ünitesine transfer edilip, takip ve tedavi altına alındı. Hastanemiz ameliyathanesinde 24 saat hizmet veren postoperatif bakım ünitesinin oluşturulması halinde bu oranın daha da azalacağını düşünmekteyiz. Tıp alanında uygulanan girişim sonuçlarının sistematik olarak değerlendirilmesi, eksik veya yanlış uygulamaların tespit edilip düzeltilmesi açısından büyük önem arz etmektedir. Araştırmamızda bazı sınırlamalar bulunmaktadır. Bunlardan ilki; acil operasyonlara ait anestezi kayıtlarımızda eksikliklere bağlı veri kayıpları bulunmaktadır. Çoklu cerrahi uygulanan, rejyonel anestezi uygulanıp sonrasında genel anesteziye geçilen hastalara, sadece tek cerrahi branş ve genel anestezi yöntemi grubunda yer verildi. Günümüzde malpraktis uygulamaları da göz önüne alındığında, klinik olarak preoperatif değerlendirme formları ve anestezi izlem kayıtlarının daha özenli tutulması gerektiği sonucuna varıldı. Bu araştırma Kırşehir bölgesindeki acil operasyonların cerrahi ve anestezi yöntemlerine ait verilerin sağlanması amacıyla yapılan ilk örnektir. Elde edilen veriler ışığında ilerleyen yıllarda daha geniş çapta epidemiyolojik çalışma yapılması planlandı. Bu verilerin diğer bölgelerde yapılacak benzer çalışmalarla birlikte ülkemiz Anesteziyoloji ve Reanimasyon veri tabanı oluşumuna katkı sağlayacağı kanaatindeyiz.

Sonuç olarak kliniğimizde sezaryen ve akut apendektomi acil operasyonlarının sıklıkla yapıldığı görülmektedir. Anestezi yöntemi olarak rejyonel anesteziye karşın genel anestezi tercih edilmektedir. Perioperatif mortalite oranı \%0.19 olarak tespit edilmiştir. Son yıllarda göç alan bölgemizdeki, sağlık intiyaçlarının planlanması ve ön hazırlık yapılabilmesi için epidemiyolojik araştırmaların sürekli olarak güncellenmesi gerektiği düşünülmüştür.

Çıkar Çatışması: Çalışmada herhangi bir çıkar çatışması yoktur.

Finansal Çıkar Çatışması: Çalışmada herhangi bir finansal çıkar çatışması yoktur.

Yazışma Adresi: Fatma Çelik, Kırşehir Ahi Evran Üniversitesi Tıp Fakültesi Anesteziyoloji Reanimasyon Anabilim Dalı, Kırşehir, Türkiye e-posta: fatma.celik@ahievran.edu.tr TIf: 05056834173

\section{KAYNAKLAR}

1. Siriphuwanun $\mathrm{V}$, Punjasawadwong $\mathrm{Y}$, Lapisatepun $\mathrm{W}$, et al. Incidence of and factors associated with perioperative cardiac arrest within 24 hours of anesthesia for emergency surgery. Risk Manag Healthc Policy 2014;7:155-62.

2. Holland R. Anaesthetic mortality in New South Wales. $\mathrm{Br} \mathrm{J}$ Anaesth. 1987;59:834-41.

3. Mitra A, Das T, Rudra A, et al. Geriatric trauma. Journal of the Indian Academy of Geriatrics. 2017;13(1):32-40.

4. Tiret L DJ, Hatton F, Vourc'h G. Complications associated with anaesthesia a prospective survey in France. Can Anaesth Soc J 1986; 33:336-44.

5. Braz LG, Modolo NS, do Nascimento $P$, et al. Perioperative cardiac arrest: A study of 53,718 anaesthetics over 9 yr from a Brazilian teaching hospital. Br J Anaesth 2006;96(5):56975.

6. Imarengiaye C. Anaesthetic management of surgical emergencies. Benin Journal of Postgraduate Medicine 2009;11(1):40-5.

7. Asai T.Airway management in patients undergoing emergency cesarean section. Journal of Anesthesia 2015;29(6):927-33.

8. Mort TC. Emergency tracheal intubation: Complications associated with repeated laryngoscopic attempts. Anesth Analg 2004;99(2):607-13.

9. Kovacs G, Sowers N. Airway management in trauma. Emerg Med Clin North Am 2018;36(1):61-84.

10. Barak $M$, Bahouth $H$, Leiser $Y$, et al. Airway management of the patient with maxillofacial trauma: Review of the literature and suggested clinical approach. Biomed Res Int 2015;2015:724032.

11. Robinson M, Davidson A. Aspiration under anaesthesia: Risk assessment and decision making. Continuing Education in Anaesthesia Critical Care \& Pain 2014;14(4):171-5.

12. Goswami S, Brady JE, Jordan DA, et al. Intraoperative cardiac arrests in adults undergoing noncardiac surgery: Incidence, risk factors, and survival outcome. Anesthesiology 2012;117(5):1018-26.

13. Rossaint $R$, Bouillon $B$, Cerny $V$, et al. The European guideline on management of major bleeding and coagulopathy following trauma: Fourth edition. Crit Care 2016;20:100.

14. Saunders DI, Murray D, Pichel AC, et al. Variations in mortality after emergency laparotomy: The first report of the UK Emergency Laparotomy Network. Br J Anaesth 2012;109(3):368-75.

15. Juan J A, Michael B-B. Mortality associated with emergency abdominal surgery in the elderly. Canadian Journal of Surgery 2003(2):111.

16. Duman $A$, Öğün CÖ, Şahin $M$, et al. Perioperatif mortalite. T Klin J Med Sci 2001;21(4):311-8.

17. Lienhart A, Auroy $Y$, Péquignot $F$, et al. Survey of anesthesia related mortality in France. Anesthesiology 2006;105(6):108797.

18. Braz LG, Braz DG, Cruz DS, et al. Mortality in anesthesia: A systematic review. Clinics (Sao Paulo) 2009;64(10):9991006.

19. Zambouri A. Preoperative evaluation and preparation for anesthesia and surgery. 4th Dept of Anesthesiology 2007;11(1):13-21. 
20. Özmen Ö, Arslan Z, Ekinci M, et al. Our management of anesthesia in elective and emergency cesarean surgery: A retrospective evaluation of the last ten years. Medeniyet Medical Journal 2016;31(4):245-9.

21. Banerjee A, Sarkar D, Bhadra B. Evaluation of anaesthetic techniques for caesarean. International Journal of Research in Medical Sciences 2018;6(5).

22. American society of anesthesiologists task force on preanesthesia evaluation. Practice advisory for preanesthesia evaluation anesthesiology 2002;96(2):485-96.

23. An updated report by the american society of anesthesiologists task force on preanesthesia evaluation. Practice advisory for preanesthesia evaluation. Anesthesiology 2012;116(3):52238.
24. Gabriel RA, A'Court AM, Schmidt UH, et al. Time of day is not associated with increased rates of mortality in emergency surgery: An analysis of 49,196 surgical procedures. J Clin Anesth 2018;46:85-90.

25. Woo T, Kim KS, Shim YH, et al. Sugammadex versus neostigmine reversal of moderate rocuronium induced neuromuscular blockade in Korean patients. Korean $\mathrm{J}$ Anesthesiol 2013;65(6):501-7.

26. Herring WJ, Woo T, Assaid CA, et al. Sugammadex efficacy for reversal of rocuronium and vecuronium induced neuromuscular blockade: A pooled analysis of 26 studies. $\mathrm{J}$ Clin Anesth 2017;41:84-91. 